\title{
Investigating the Effects of Surface Adsorbates on Gold and Palladium Deposition on Carbon
}

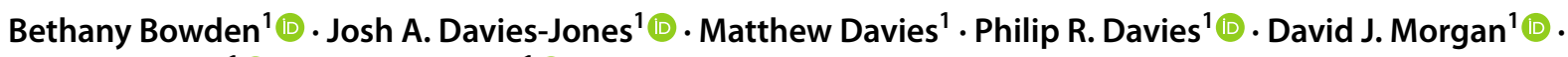 \\ Mala A. Sainna ${ }^{1}$ (1) David J. Willock ${ }^{1}$ (i)
}

Accepted: 10 March 2021 / Published online: 30 March 2021

(c) The Author(s) 2021

\begin{abstract}
Surface functional groups have a strong influence on the deposition and final state of nanoparticles adsorbed on to the surface, a role discussed by Professor Spencer in his work. This tribute to Spencer explores the formation of hydroxyls, thiosulfates, sulfites and sulfur atoms on carbon (HOPG) surfaces and their effect on the deposition of gold and palladium from aqueous solutions. Hydroxyls formed from ammonium hydroxide treatment have identical behaviour to those formed by acid treatment, and gold adsorption from $\mathrm{Au}^{3+}$ solutions gives $\mathrm{Au}^{0}$ initially, with $\mathrm{Au}^{3+}$ formed at higher concentrations on these surfaces. In contrast, palladium adsorption is hindered by the presence of the hydroxyls and there is no indication of any reduction to the metallic state. Ammonium thiosulfate adsorbs dissociatively from aqueous solutions on HOPG if the surface is pre-activated by the presence of surface hydroxyls. At low concentrations of ammonium thiosulfate, adsorbed sulfite and sulfur are formed in equimolar concentrations whereas adsorption of high concentrations of ammonium thiosulfate gives some degree of molecular adsorption, with evidence in XP spectra for an ammonium ion and a sulfur 2p peak at $282.9 \mathrm{eV}$ attributed to the undissociated thiosulfate ion. Both sulfur and the sulfite are stable at the surface in neutral solutions but the sulfite desorbs when treated with acidified solutions $(\sim \mathrm{pH} \leq 6)$. These two groups are also stable at $373 \mathrm{~K}$ but begin to desorb by $473 \mathrm{~K}$. Exposure to a weak chloroauric acid solution causes the desorption of the sulfite and formation of a gold species with an XP binding energy of $84.6 \mathrm{eV}$; we cannot determine from the present data whether this peak is due to a $\mathrm{Au}(\mathrm{I})$ state or very small nanoparticles of $\mathrm{Au}(0)$.
\end{abstract}

\section{Graphic Abstract}

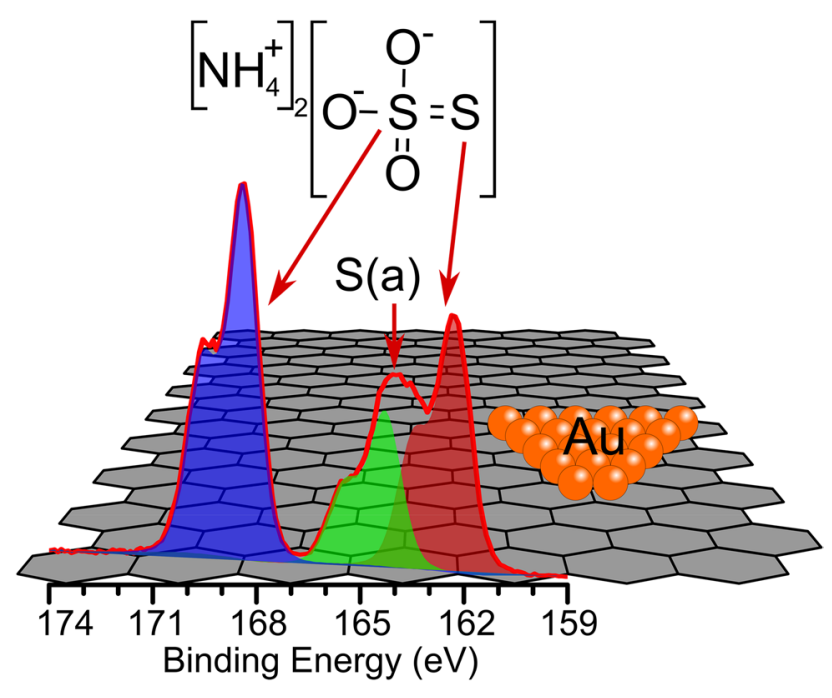

Keywords Thiosulfate $\cdot$ HOPG $\cdot$ AFM $\cdot$ XPS $\cdot$ Sulfite $\cdot$ Sulfur $\cdot$ Gold $\cdot$ Palladium

Extended author information available on the last page of the article 


\section{Introduction}

Amongst the most important contributions made by Professor Michael Spencer to the field of catalysis are several focused on the nature of the metal nanoparticles that form the active component of many heterogeneous catalysts. In 1986 for example, Spencer discussed surface atom mobility on iron, copper and platinum nanoparticles [1] proposing that this mobility allows the nanoparticles to reach their own stable states and this might account for the surprising reproducibility of catalytic activity in many systems despite varying preparation conditions. This work anticipated, in some respects, the scanning probe experiments a decade later that showed how important atom mobility can be in surface reaction mechanisms [2, 3]. In another example, Spencer considered [4] the SMSI effect in the $\mathrm{Pt} / \mathrm{TiO}_{2}$ system from a thermodynamic perspective and discussed the possible roles of water and potassium as surface species modifying the behaviour of the nanoparticle/substrate interface. Whereas Spencer was primarily concerned with the nature of the active particle during catalysis, our focus has recently been on the initial formation of such nanoparticles at the surface of carbon catalyst supports and in particular, the role of the functional groups on the support in their nucleation and stabilisation [5-7]. The importance of surface species in these systems is widely recognised [8-12], however, the complex nature of the carbons typically used as supports for catalysts has hindered attempts to explore the role of specific species. We have addressed this issue by selecting highly ordered pyrolytic graphite (HOPG), as an idealised carbon substrate to functionalise. Whilst the $\mathrm{sp}^{2}$ nature of a graphite surface does not reflect the majority $\mathrm{sp}^{3}$ species present in most carbons used as catalyst supports, graphite's uniform surface chemistry allows us to investigate the role of individual functional groups in isolation [5, $6,13]$. We have adopted an experimental protocol that mirrors that used in many catalyst preparation routines and have begun to be able to comment directly on the role of specific functional groups. Acid treatment of graphite surfaces generates $\mathrm{OH}$ or $\mathrm{C}=\mathrm{O}$ groups, the former largely transforming into the latter on heating. DFT calculations [5] show that both types of oxygen interact with gold and suggest that nucleation should occur in both cases. This was confirmed experimentally [7], and gold deposition from an aqueous solution at $\sim \mathrm{pH} 5-6$ was shown to require the oxygen functional groups for nucleation to occur at all on HOPG. OH(a) groups reduced $\mathrm{Au}^{3+}$ ions to a metallic state whereas the $\mathrm{C}=\mathrm{O}$ groups result in gold deposition in a $\mathrm{Au}^{3+}$ state.

In the present paper, we expand our previous investigations to look at different preparation methods for the surface hydroxides, different functional groups, and a different cation. Specifically we examine graphite surfaces treated with hydroxides produced from a basic solution instead of an acidic one, sulfur containing functional groups (as used in the recently commercialised gold/ carbon catalyst for vinyl chloride synthesis [14]) and the effect of surface hydroxyl groups on palladium nucleation.

\section{Experimental}

HOPG samples ( $10 \mathrm{~mm}$ square, ZYH quality, supplied by Scanwel Ltd, UK) were cleaned before each experiment by exfoliation of the top few graphene monolayers using adhesive tape. Treatment involved the placement of a $100 \mu$ droplet of fresh diluted (see below) acid or base on the HOPG surface, allowing the system to stand for $30 \mathrm{~min}$ before drying under a pure helium or nitrogen stream. Aqueous solutions wet the HOPG surfaces effectively. For metal deposition, $100 \mu \mathrm{l}$ droplet of precursor solution $\left(\mathrm{HAuCl}_{4} \cdot 3 \mathrm{H}_{2} \mathrm{O}\right.$, Sigma-Aldrich, $99.999 \%$ or acidified palladium (II) chloride, Sigm-Aldrich ReagentPlus ${ }, 99 \%$ ), was placed on the pre-treated sample and left for $1 \mathrm{~min}$. The sample was subsequently dried under a stream of helium or nitrogen for $2 \mathrm{~min}$. The $\mathrm{pH}$ of the $1 \times 10^{-5} \mathrm{M}$ and $2 \times 10^{-6} \mathrm{M}$ gold solutions were measured to be 5.26 and 5.63 before contact with the HOPG surface. To treat the HOPG surfaces with ammonium thiosulfate $\left(\left(\mathrm{NH}_{4}\right)_{2}\left(\mathrm{~S}_{2} \mathrm{O}_{3}\right)\right)$ a $100 \mu$ droplet of $0.2 \mathrm{M},\left(\mathrm{NH}_{4}\right)_{2}\left(\mathrm{~S}_{2} \mathrm{O}_{3}\right)$ was added to the surface of clean HOPG and left to stand in air for $30 \mathrm{~min}$. The sample was then dried under a stream of He for $15 \mathrm{~s}$. Where indicated, selected samples were heated for $1 \mathrm{~h}$ after surface treatment and allowed to cool to ambient temperature before analysis.

Ultra-pure water ("UPW", Millipore, resistivity ca $19 \mathrm{M} \Omega \mathrm{cm}$ ) was used for dilution of the acids and the gold solution before surface treatment and for control experiments that replicated dosing and analysis conditions. We discovered that these experiments are extremely prone to contamination of the surface by silicon oxides which may have originated from the tape used for strip cleaning the HOPG. Despite precautions, silicon was a frequent contaminant seen in the XPS of the samples and resulting in a dominant $\mathrm{SiO}_{\mathrm{x}}$ peak in the $\mathrm{O}(1 \mathrm{~s})$ region of the spectrum. In these cases, the data was abandoned, and the samples cleaned again.

X-ray photoelectron spectroscopy (XPS) was performed on a Thermo Fisher Scientific K-alpha ${ }^{+}$spectrometer using a micro-focused monochromatic Al x-ray source (72 W) over an area of approximately $400 \mu \mathrm{M}$. Pass energies of $150 \mathrm{eV}$ and $40 \mathrm{eV}$ were used for survey and high resolution scans respectively with $1 \mathrm{eV}$ and $0.1 \mathrm{eV}$ step sizes. Samples were mounted on AFM stubs for ease of handling which 
necessitated the use of charge neutralisation with a combination of low energy electrons and argon ions.

The XPS data was analysed using CasaXPS v2.3.23 using Scofield sensitivity factors and an energy compensation factors to account of the electron inelastic mean free path, which is approximated using $\mathrm{KE}^{\mathrm{n}}$, where $\mathrm{n}=-0.6$. All binding energies were referenced to the $\mathrm{C}(1 \mathrm{~s})$ peak taken to be $284.5 \mathrm{eV}$. Curve fits were made with spin orbit splitting components for the $\mathrm{Au}(4 \mathrm{f}), \mathrm{Pd}(3 \mathrm{~d}), \mathrm{S}(2 \mathrm{p})$ and $\mathrm{Cl}(2 \mathrm{p})$ spectra fixed at 3.7, 5.3, 1.16 and $1.6 \mathrm{eV}$, and relative areas of $4: 3,3: 2,1.96: 1$ and $2: 1$, respectively. $\mathrm{Au}(4 \mathrm{f})$ and $\mathrm{Pd}(3 \mathrm{~d})$ spectra were fitted using CasaXPS' Finite Lorentzian ("LF") lineshape, which is a Voigt type function with a dampening factor to drive the Lorentzian tail down to the baseline to minimise over estimation of peak areas. Fitting of the $\mathrm{Au}$ and Pd regions were made using models derived from the respective bulk metal foils, the FWHM of the species were therefore determined by the $4 \mathrm{f}_{7 / 2}$ and $3 \mathrm{~d}_{5 / 2}$ peaks of the foils, but allowed to vary by ca. $0.3 \mathrm{eV}$. The extent of metal reduction under $\mathrm{x}$-ray irradiation was assessed by recording the $\mathrm{Au}(4 \mathrm{f})$ region at both the start and completion of a set of XP spectra. Typically, no increase in the proportion of $\mathrm{Au}^{0}$ was evident after 30-40 min of irradiation. It is worth noting here, that the experimental protocol of treating samples externally to the spectrometer makes quantitative estimates between samples difficult and thus in the present paper, quantification is only used to compare concentrations of surface components on individual samples at the same treatment stage. However, the observed binding energies of the components within the spectra were reproducible from sample to sample and general trends can be deduced.

AFM images were acquired on a Bruker Veeco Multimode system in tapping mode using silicon nitride tips. Multiple images were recorded of several different sites on the surface and on several different samples and images were analysed using WSxM software [15].

\section{Results and Discussion}

\subsection{Nucleation and Deposition of Palladium from Palladium Chloride}

Palladium concentrations of the same order as previously used for gold deposition $\left(1 \times 10^{-6} \mathrm{M}\right)$ resulted in no adsorption at the HOPG surface but at $1 \times 10^{-5} \mathrm{M}$ palladium was observed in the XP spectra (Fig. 1). On the surface pre-treated with ultra-pure water the expected Pd (3d) doublet is present with the $3 \mathrm{~d}_{5 / 2}$ peak at $338 \mathrm{eV}$ approximately $0.2 \mathrm{eV}$ higher than is typical of $\mathrm{PdCl}_{2}$ (Figure $\mathrm{S} 1$ and References [16-18]). There is also a single chlorine state present with the $\mathrm{Cl}\left(2 \mathrm{p}_{3 / 2}\right)$ peak at $198.4 \mathrm{eV}$ corresponding to a metal coordinated chloride and this is the first clue that palladium chloride behaves differently to gold. Deposition of gold on HOPG from chloroauric acid solutions usually gives rise to two chlorine states with $2 \mathrm{p}_{3 / 2}$ peaks at $198 \mathrm{eV}$ and $200 \mathrm{eV}$ [19] assigned to chlorides bound to the metal and carbon respectively (see Fig. 3 for an example). In the present case, there is no evidence of chlorine associated with the carbon support. The $\mathrm{Cl}: \mathrm{Pd}$ ratio of the adsorbed species is lower than expected for $\mathrm{PdCl}_{2}$, averaging 1.3:1. This discrepancy is not accounted for by the very small degree of reduction of palladium which is evident when comparing spectra before and after exposure to the x-rays (not shown) but a contributing factor could be the replacement of chloride ions by hydroxides in solution (note $\mathrm{Pd}(\mathrm{OH})_{2}$ is not expected to occur in solution [20] below a pH of $\sim 10$ [21]). Figure. 1 shows that pre-treating the HOPG surface with higher concentrations of acid (and thereby generating higher concentrations of $\mathrm{OH}(\mathrm{a})$ ) does not lead to any chemical reduction of the deposited palladium chloride species, as was the case with gold, but it does have the effect of decreasing the extent of deposition of palladium species (Fig. 1e). The $\mathrm{O}(1 \mathrm{~s})$ peak at $532.5 \mathrm{eV}$ can be attributed to $\mathrm{OH}$ (a) which is unaffected by the adsorption of the palladium salt, the weak peak at $\sim 535.5 \mathrm{eV}$ due to $\mathrm{Pd}\left(3 \mathrm{p}_{3 / 2}\right)$, confirming the small extent of adsorption. In the solutions we are using, the aqueous palladium-chloride species is likely to be negatively charged [20] and therefore increasing the number of adsorbed $\mathrm{OH}$ groups at the surface may increase the negative charge on the surface and thus repel the ion [22].

AFM images of the HOPG surfaces after exposure to palladium chloride solutions also reflect very different behaviour between the palladium and gold chlorides: $\mathrm{PdCl}_{2}$ deposited on the ultra pure water treated surface results in a number of regular features in the AFM images, approximately $3 \mathrm{~nm}$ in height with diameter of $\sim 30 \mathrm{~nm}$ (Fig. 2a, b, c). These features are not present on clean graphite and we tentatively assign them to clusters of adsorbed $\mathrm{PdCl}_{2}$. There are far fewer features present after palladium chloride is dosed onto nitric acid treated HOPG samples. A small number of $\sim 3 \mathrm{~nm}$ tall features are evident near step edges but the majority of the surface looks very flat, Fig. 2 AFM images of treated HOPG surfaces; (a) treated with $0.25 \mathrm{M} \mathrm{HNO}_{3}$; (b) $1 \times 10^{-5} \mathrm{M}$ aqueous solution of $\mathrm{PdCl}_{2}$ after treatment withultra pure water; (c) $1 \times 10^{-5} \mathrm{M}$ aqueous solution of $\mathrm{PdCl}_{2}$ after treatment $2 \mathrm{M}$ $\mathrm{HNO}_{3}$;. (d) Line profiles from the AFM images (c). As Fig. 2a, shows and from previous work [5, 6, 13], nitric acid oxidises the HOPG surface leading to areas of local delamination, typically $100-150 \mathrm{~nm}$ wide and $3-10 \mathrm{~nm}$ high. In this case, and similar to the effect of heating [5, 6], the exposure of the surface to palladium chloride solution appears to remove some of these features. 

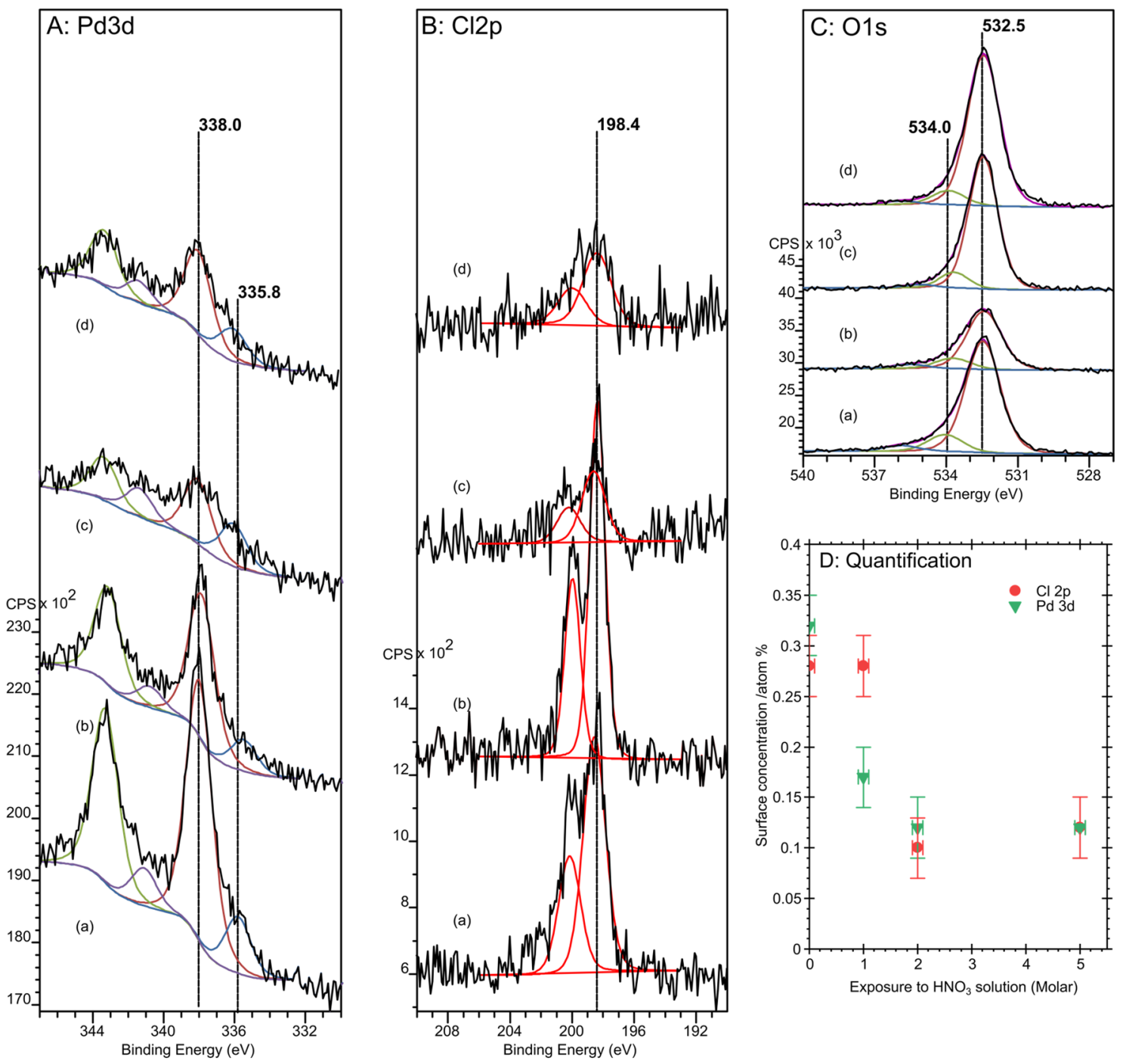

Fig. 1 a-c, XP spectra of HOPG surface pre-treated with a range of concentrations of $\mathrm{HNO}_{3}$ and, after drying, exposed to $1 \times 10^{-5} \mathrm{M}$ aqueous solutions of $\mathrm{PdCl}_{2}$; (a) $\mathrm{Pd}$ adsorption at a surface pre-treated

\subsection{Functionalisation of a HOPG Surface with Aqueous Hydroxide lons}

We have shown that the oxidation of HOPG surfaces by low concentrations of mineral acids leads to functionalisation with $\mathrm{OH}(\mathrm{a})$ groups [13]. Since the energy required to break one of the $\mathrm{C}-\mathrm{C}$ bonds is considerable, we have proposed that this reaction is occurring at existing defects on the surface $[5,6]$. The question we wished to examine was whether $\mathrm{OH}$ species could be formed directly at the surface from a basic solution. Initial experiments with sodium hydroxide showed oxygen functionalisation of the surface in the XP spectra and the generation of typical 3-4 nm high $\mathrm{OH}$ related features in the AFM images but the XPS also showed sodium deposition which creates a possible with pure water; (b) pre-treated with $1.0 \mathrm{M} \mathrm{HNO}_{3}$; (c) $2.0 \mathrm{M} \mathrm{HNO}_{3}$; (d) $5.0 \mathrm{M} \mathrm{HNO}_{3}$; d Quantification of the palladium and chlorine surface concentrations

complicating factor for the deposition of the gold or other cations. Instead, we have explored functionalisation of the surface with ammonium hydroxide solutions and as Fig. 3 shows, a functionalisation of the surface similar to that observed with the weak acids does occur. Furthermore, the $\mathrm{OH}$ groups generated at the surface also induce nucleation of gold from a chloro auric acid solution. The initial deposition is of a reduced gold state but at higher concentrations of the gold solution, $\mathrm{Au}^{3+}$ dominates together with the deposition of an associated chloride counter ion. It's worth noting that whilst achieving the same effect as treating the HOPG with acids, a concentration of at least $5 \mathrm{M}$ ammonium hydroxide was required to generate significant functionalisation of the carbon compared to only $0.2 \mathrm{M}$ of the acids investigated. 

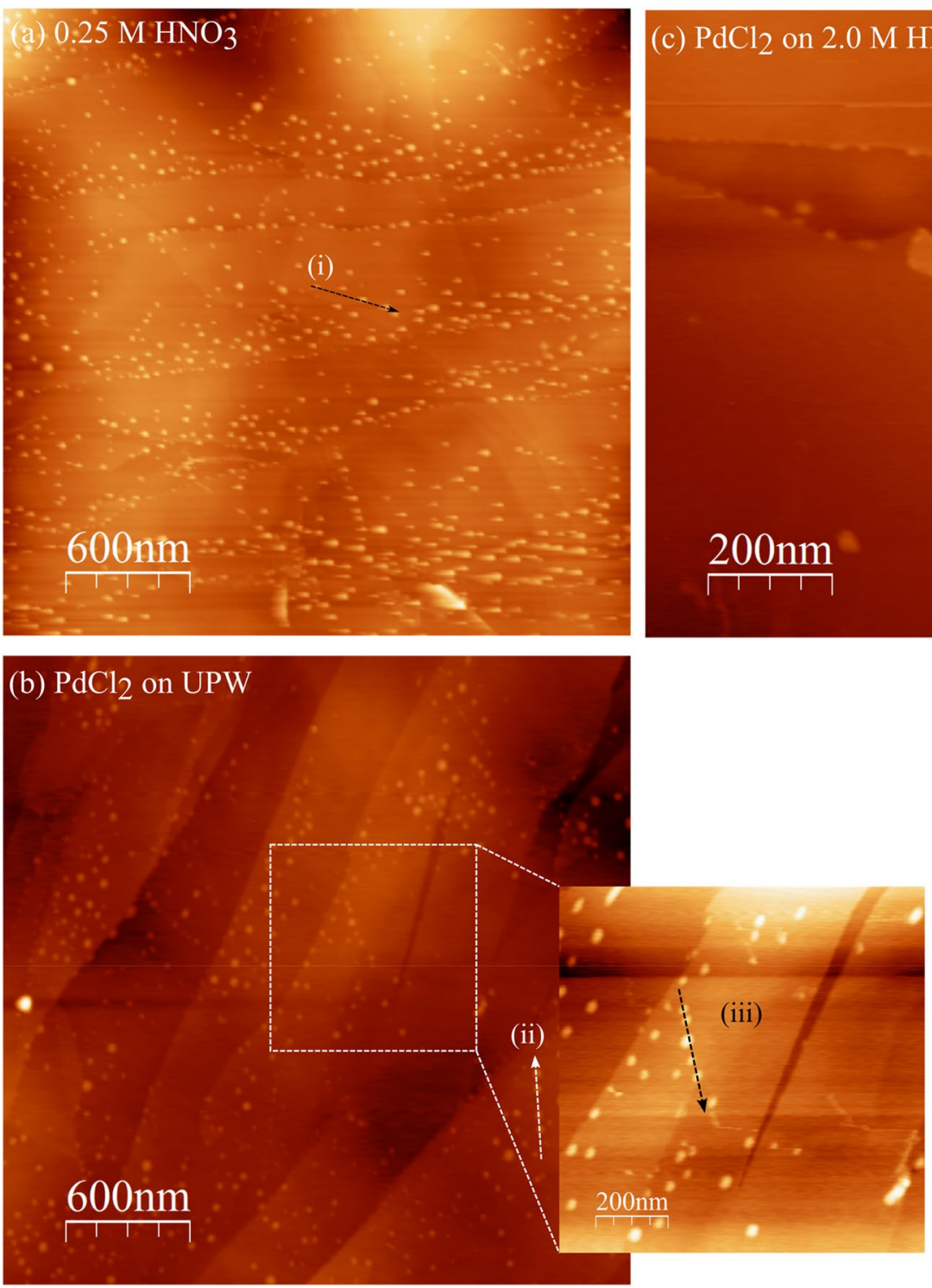
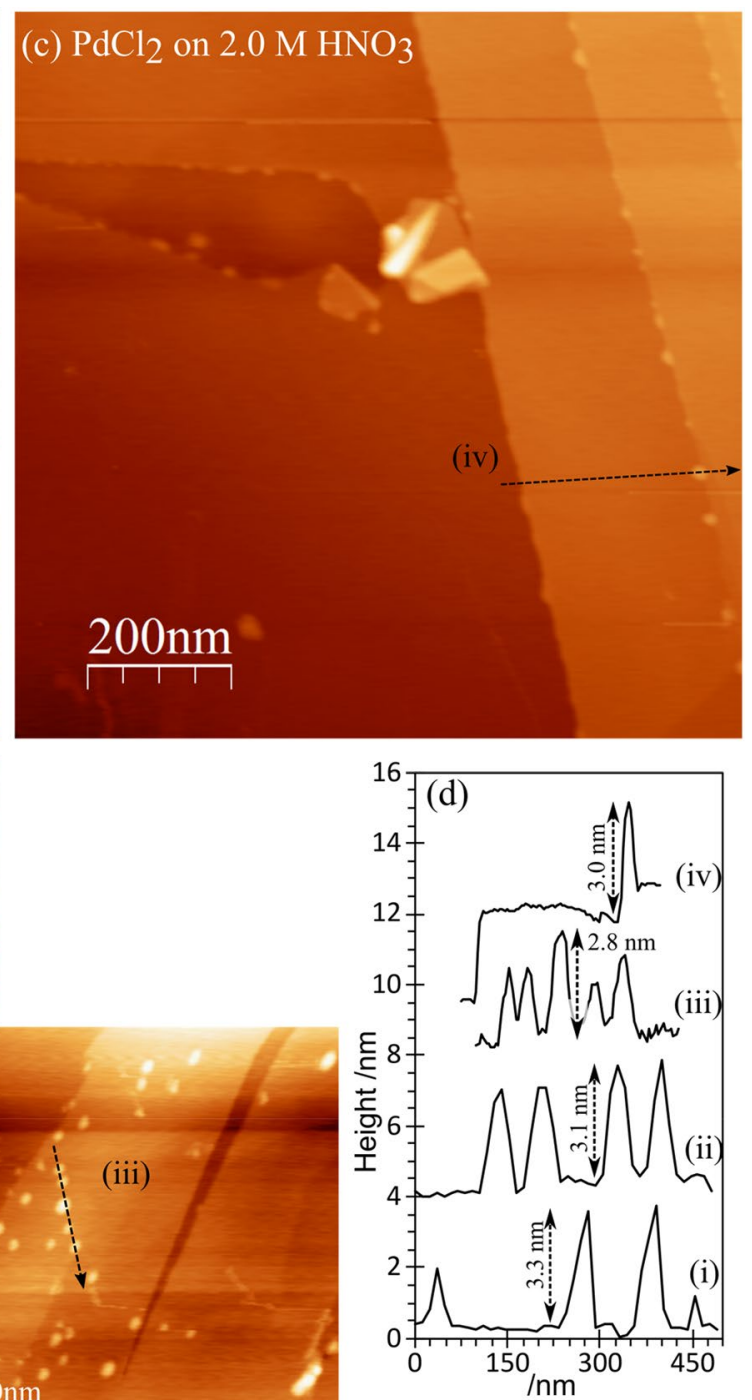

Fig. 2 AFM images of treated HOPG surfaces; a treated with $0.25 \mathrm{M} \mathrm{HNO}_{3} ; \mathbf{b} 1 \times 10^{-5} \mathrm{M}$ aqueous solution of $\mathrm{PdCl}_{2}$ after treatment withultra pure water; $\mathbf{c} 1 \times 10^{-5} \mathrm{M}$ aqueous solution of $\mathrm{PdCl}_{2}$ after treatment $2 \mathrm{M} \mathrm{HNO}_{3}$. d Line profiles from the AFM images

\subsection{Functionalisation of HOPG Surface with Aqueous Ammonium Thiosulfate Solutions}

Johnston et al. have demonstrated [14, 23] that soft donors such as thiosulfates are an effective method of stabilising gold nanoparticles in a cationic form on carbon supports, but how the thiosulfates interact with the carbon is not known and to start to unpick this phenomenon we have studied the adsorption of thiosulfate onto HOPG substrates and their subsequent effect on gold adsorption from solution. To our knowledge, there has not been a study of the adsorption of ammonium thiosulfate on either clean or functionalised HOPG surfaces.
Reference spectra of two different thiosulfates are shown in the supplementary data Figure S2, and show good agreement to data in the literature [24, 25]. Gold sodium thiosulfate solid gives a spectrum with two components in the $\mathrm{S}(2 \mathrm{p})$ region, characterised by $\mathrm{S}\left(2 \mathrm{p}_{3 / 2}\right)$ peaks at $163.6 \mathrm{eV}$ and $\sim 169.1 \mathrm{eV}$, the latter attributed unambiguously to the $\mathrm{SO}_{3}$ group. The two states have a concentration ratio of 1:1.2 possibly reflecting the surface termination of the crystals. $\mathrm{The} \mathrm{Au}^{+} 4 \mathrm{f}$ peak is at $84.6 \mathrm{eV}$, and a bit less than half the concentration of the $163.6 \mathrm{eV}$ sulfur peak consistent with the molecular stoichiometry. A reference sample of ammonium thiosulfate was obtained by allowing a $0.2 \mathrm{M}$ solution to dry on a HOPG surface giving a precipitate that was visible 

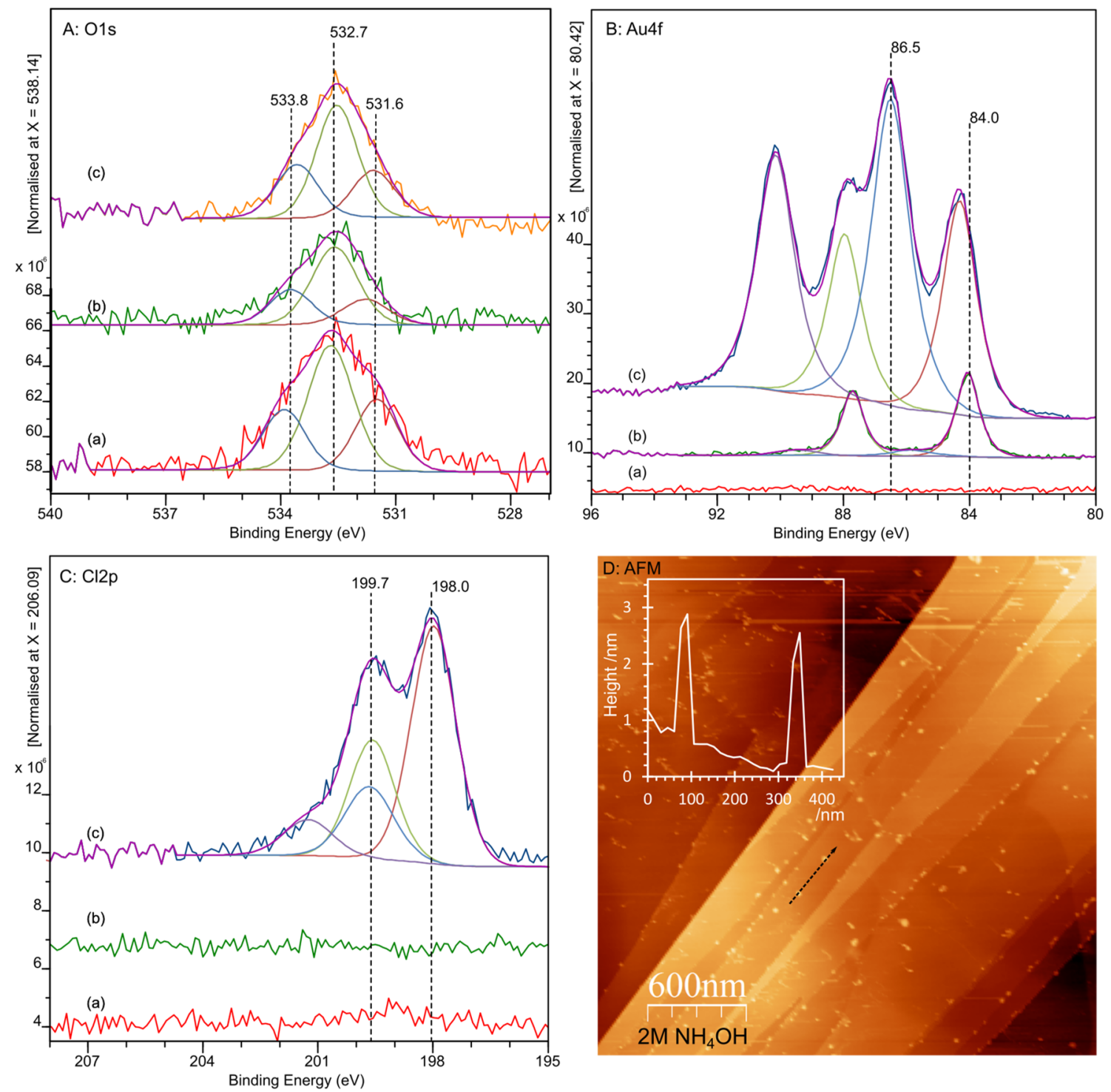

Fig. $3 \mathrm{NH}_{4} \mathrm{OH}$ treatment of HOPG surfaces results in the oxidation of the surface to give primarily hydroxide species. These enable the nucleation of gold at the surface from $\mathrm{HAuCl}_{4}$ solutions. a-c, $\mathrm{XP}$ spectra of the $\mathrm{O}(1 \mathrm{~s}), \mathrm{Au}(4 \mathrm{f})$ and $\mathrm{Cl}(2 \mathrm{p})$ regions: a the presence of $\mathrm{OH}(\mathrm{a})$ after treatment with $5 \mathrm{M} \mathrm{NH}_{4} \mathrm{OH}$. b After exposure of (a) to $5.0 \times 10^{-6} \mathrm{M} \mathrm{HAuCl}_{4}$; c After exposure of (a) to $1.0 \times 10^{-5} \mathrm{M}$

to the eye. For this sample, the $\mathrm{S}(2 \mathrm{p})$ spectra show a third component in addition to those that can be assigned to the two sulfur states in the thiosulfate molecule. The third state has a $\mathrm{S}\left(2 \mathrm{p}_{3 / 2}\right)$ component at $164.2 \mathrm{eV}$ and can be assigned to atomic sulfur at the HOPG surface, implying the dissociation of approximately half the thiosulfate. Interestingly, the $\mathrm{SO}_{3}$ peak at $168.4 \mathrm{eV}$, has approximately the same surface concentration as the other two peaks combined, indicating that it consists of a combination of $\mathrm{SO}_{3}$ (a) and $\mathrm{S}_{-} \mathrm{SO}_{3}$ (a) and indicating that dissociation has little effect on the binding energy of this already very positively charged sulfur.
$\mathrm{HAuCl}_{4}$; At low concentrations of the gold solution, the initial adsorption is gold metal but higher concentration solutions result in extensive $\mathrm{Au}^{3+}$ deposition with the associated chloride counter ion. The AFM images in $\mathbf{d}$, show similar features on the surface after $\mathrm{NH}_{4} \mathrm{OH}$ treatment as we observed with weak acids

Furthermore, the stoichiometry suggests that all the sulfur stays on the surface on dissociation of the ammonium thiosulfate. The ammonium ion is also present with a peak in the $\mathrm{N}(1 \mathrm{~s})$ region at $402.1 \mathrm{eV}$ and a surface coverage similar to that of the sulfur peak at $182.4 \mathrm{eV}$, a little more than half of that of the $\mathrm{SO}_{3}$ group.

At a clean HOPG surface, XP spectra show no adsorption of any sulfur containing species after treatment with $0.2 \mathrm{M}$ ammonium thiosulfate (Fig. 4a), although there is a small increase in the oxygen species on the surface; the latter is to be expected after exposure to an aqueous solution. 

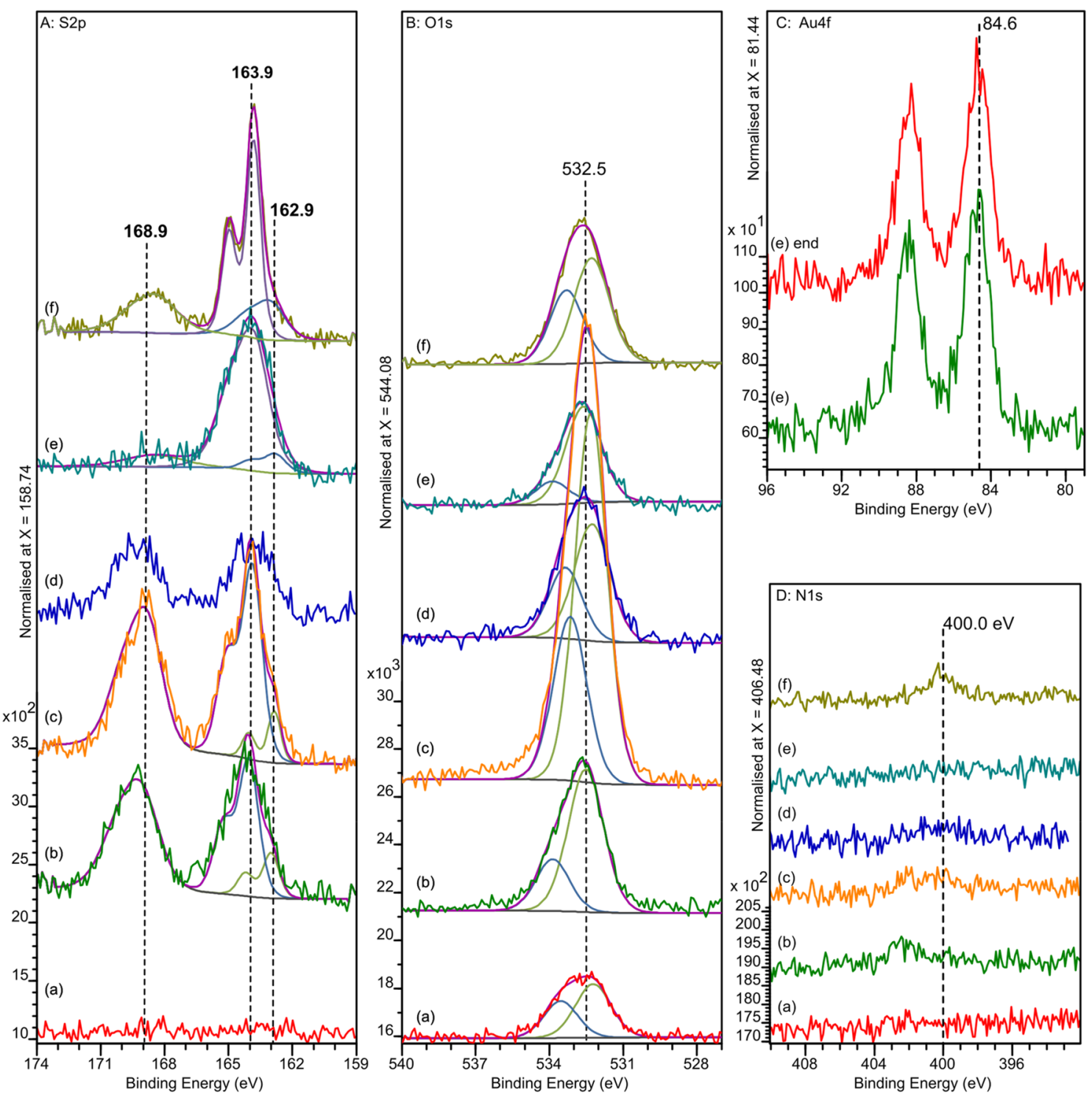

Fig. 4 XP spectra of ammonium thiosulfate adsorption $(0.2 \mathrm{M})$ on clean and functionalised surfaces and the effect on gold adsorption. In the $S(2 p)$ region, the $2 p_{3 / 2}$ and 2 p1/2 fitted components are combined to show the three separate states of sulfur more clearly. (a)

Adsorption does occur if the surface is first functionalised with hydroxide groups by acid pre-treatment (Fig. 4b). At least two sulfur states are now evident on the surface, characterised by $\mathrm{S}\left(2 \mathrm{p}_{3 / 2}\right)$ components at $\sim 164 \mathrm{eV}$ and $\sim 169.0 \mathrm{eV}$. From the reference spectra in Figure S2, the higher binding energy component can be unambiguously attributed to $\mathrm{SO}_{3}$ (a) with the associated oxygen contributing to the $\mathrm{O}(1 \mathrm{~s})$ peak at $532.5 \mathrm{eV}$. The $\mathrm{S}: \mathrm{O}$ ratio for the $\mathrm{S} 2 \mathrm{p}$ and $\mathrm{O}$ $1 \mathrm{~s}$ signals assigned to $\mathrm{SO}_{3}(\mathrm{a})$ is higher than expected for - $\mathrm{SO}_{3}$, at 1:4.4, but $\mathrm{OH}(\mathrm{a})$ would also be expected to be

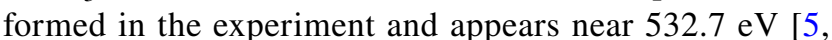
$6]$ possibly accounting for the extra peak area. The lower binding energy peak in the $S(2 p)$ region can be attributed to
$\left(\mathrm{NH}_{4}\right)_{2} \mathrm{~S}_{2} \mathrm{O}_{3}$ on clean HOPG; (b) $\left(\mathrm{NH}_{4}\right)_{2} \mathrm{~S}_{2} \mathrm{O}_{3}$ on $\mathrm{HCl}$ treated HOPG; c after heating (b) to $373 \mathrm{~K}$; (d) after heating (c) to $473 \mathrm{~K}$; (e) Exposure of (b) to $10^{-6} \mathrm{M} \mathrm{HAuCl}_{4}$ solution. (f) Surface in (b) treated with $0.5 \mathrm{M} \mathrm{HNO}_{3}$

adsorbed sulfur showing almost complete dissociation of the thiosulfate, although there is some evidence for more than one sulfur state being present in the lower binding energy peak envelope. The adsorbed components are stable on heating to $373 \mathrm{~K}$ but are beginning to desorb by $473 \mathrm{~K}$.

We conclude that the adsorption of ammonium thiosulfate onto hydroxyl covered graphitic surfaces from aqueous solution leads primarily to dissociative adsorption forming $\mathrm{SO}_{3}$ (a) and $\mathrm{S}$ (a) with approximately $20 \%$ of the adsorbate remaining in the molecular form.

Exposure of the acid/thiol treated surface to an aqueous solution of chloroauric acid results in the selective loss of the $\mathrm{SO}_{3}$ (a) species but no change in the lower binding energy 
state (Fig. 4). There is an associated deposition of gold at the surface similar to that expected on an acid treated HOPG surface with a final gold surface concentration approximately $1 / 4$ that of the sulfur concentration. The $\mathrm{Au}(4 \mathrm{f})$ binding energy of $84.6 \mathrm{eV}$ is $\sim 0.6 \mathrm{eV}$ above that expected for the metallic state and was not affected by exposure to the $\mathrm{x}$-ray beam for $>30 \mathrm{~min}$. There is no adsorption of any chloride counter ion or any change in the oxygen spectra to suggest the presence of gold hydroxides. Interestingly, the binding energy of $84.6 \mathrm{eV}$ is identical to that expected for a $\mathrm{Au}^{+}$state but the stability of the peak may suggest the presence of very small nanoparticles of gold rather than $\mathrm{Au}^{+}$. Freund et al. have shown that a complete attribution of the charge state of gold is best obtained from a modified Auger parameter $[26,27]$. We have not been able to access the relevant gold Auger peaks with the current experiments but will explore it in future work. Treatment with $0.5 \mathrm{M} \mathrm{HNO}_{3}$ solution had a similar effect to the aqueous gold solution as shown in (Fig. 4f), where the $168 \mathrm{eV}$ doublet is mostly removed after treatment with the acid. Interestingly, the resolution of the
$164 \mathrm{eV}$ doublet is also improved by the acid treatment suggesting a reduction in the range of environments of the S(a) perhaps indicating that there were some residual interactions between the adsorbed sulfur and the sulfite even though the $\mathrm{S}-\mathrm{S}$ bond was broken.

We cannot definitively rule out the adsorbed thiosulfate having any effect on gold deposition from solution, but there is no direct evidence (other than the unusual $\mathrm{Au}(4 \mathrm{f})$ binding energy) that this is the case; the behaviour of the gold is very similar to the case of adsorption on a surface functionalised with a weak acid.

The AFM data is less clear cut than the XPS, (Fig. 5). Treatment of the clean HOPG surfaces with thiosulfate solutions leads to no significant changes, consistent with the XP data showing no adsorption. Furthermore, thiosulfate adsorption after a pre-treatment with $\mathrm{HCl}$, shows similar delamination effects to those observed when the surface is only treated with the weak acids. Finally, AFM images of the thiosulfate treated surface exposed to gold solution do not show any features that can be attributed to the adsorption
Fig. 5 AFM images of acid treated HOPG surfaces treated with ammonium thiosulfate and gold solutions. a HOPG surface after treatment with $0.2 \mathrm{M} \mathrm{HCl}$ followed by direct exposure to $0.2 \mathrm{M}\left(\mathrm{NH}_{4}\right)_{2}\left(\mathrm{~S}_{2} \mathrm{O}_{3}\right)$. b Exposure of (a) to $10^{-6} \mathrm{M} \mathrm{HAuCl}_{4}$ solution. $\mathbf{c}$ Line profiles from (a) and (b)
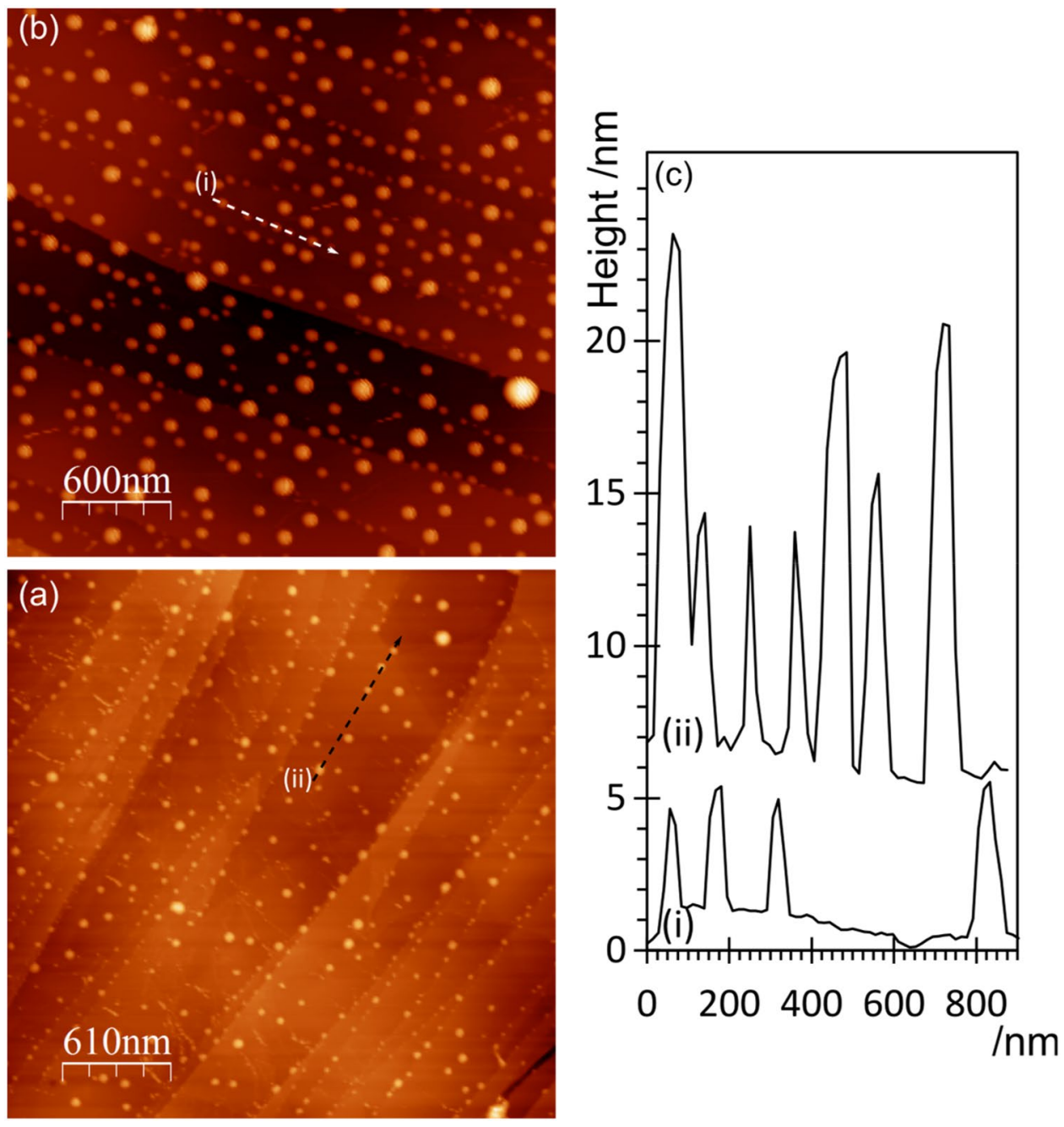
of gold. This would correlate with the interpretation of the $84.6 \mathrm{eV}$ peak in the XP data as resulting from nanoparticles of gold that are too small to be imaged at this resolution but cannot be considered definitive. Further conclusions require imaging at much higher resolution.

\section{Conclusions}

In this paper we have extended our studies of the effects of the functionalisation of graphite surfaces on the deposition of active metal components. The experiments are relevant not only to the catalysis community but to a number of other areas in which metal nanoparticles are associated with carbon allotropes such as graphene and carbon nanotubes. Whereas there is good evidence that gold can be reduced by hydroxides at the carbon surface, we have found that this does not occur when palladium is adsorbed from palladium chloride solutions. Furthermore the adsorption of palladium ions at the surface is actively hindered by the presence of $\mathrm{OH}$ groups at the surface. Freund et al. [28] saw similar effects with deposition of palladium on a magnesium oxide surface from an alkaline solution of palladium chloride. At the $\mathrm{pH}$ used in those studies, the palladium was expected to be present in solution as a hydroxide and this is the species that was observed at the surface after deposition. Reduction of the palladium to metal nanoparticles was only achieved by heating to $\sim 700 \mathrm{~K}$. In our experiments at lower $\mathrm{pH}, \mathrm{Pd}$ would be expected to be present predominantly as the chloride in solution [21] whereas Au will form partial hydroxides $\left(\left[\mathrm{AuCl}_{2}(\mathrm{OH})_{2}\right]^{-}\right.$and $\left.\left[\mathrm{AuCl}(\mathrm{OH})_{3}\right]^{-}\right)$[29] These observations reflect the higher affinity of Pd for chloride and so may explain the differences seen in the deposition of the metals from their chloride salts on the HOPG surface.

Thiosulfate adsorption from solution is predominantly dissociative leading to the formation of adsorbed sulfite and sulfur, characterised by $S(2 p)$ binding energies of 168.9 and $163.9 \mathrm{eV}$ respectively. Adsorption of thiosulfate from solutions with higher concentrations results in some molecular adsorption of the thiosulfate indicated by a $S(2 p)$ peak at $\sim 162.9 \mathrm{eV}$. Subsequent exposure of the surface to an acidic aqueous solution leads to the desorption of the sulfite groups but no discernible change in the concentration of the adsorbed sulfur atoms. However, a sharpening of the $S(2 p)$ spectrum after acid treatment may indicate a reduction in the variety of sulfur adsorption environments and hints that whilst the $\mathrm{S}-\mathrm{S}$ bond is broken when the thiosulfate adsorbs, there remains a degree of interaction. Thiosulfates have been exploited commercially [14] to create stable, gold based catalysts on carbon supports, our experiments show that thiosulfates adsorbed directly onto the carbon surface interact only very weakly, if at all, with gold subsequently deposited from solution. The adsorbed sulfite groups desorb as was the case with treatment with an acid solution and the adsorbed sulfur atoms appear unaffected by the presence of the gold. However, there is a significant and reproducible $\sim 0.5 \mathrm{eV}$ shift upwards in XP binding energy of the deposited gold from when it is adsorbed in the presence of a hydroxide alone. This could signify the formation of a predominantly small nanoparticles of gold at the surface or it may reflect a degree of coordination of the deposited gold to the adsorbed sulfur. The AFM images are not sufficiently highly resolved to discriminate between these different scenarios. Commercial catalyst preparation involves complexation of the gold ion in solution and this will form the subject of future investigations into this system.

Supplementary Information The online version contains supplementary material available at https://doi.org/10.1007/s11244-021-01423-2.

Funding This work was supported by EPSRC Grant EP/I038748/1. B.B. was supported by a Cardiff University summer studentship under the CUROP scheme. XPS data collection was performed at the EPSRC National Facility for XPS ('HarwellXPS'), operated by Cardiff University and UCL, under contract No. PR16195.

Data Availability The datasets generated and/or analyzed during the current study are available in the Cardiff University repository [https:// doi.org/10.17035/d.2021.0132067566].

\section{Declarations}

Conflict of interest The authors declare that they have no competing interests.

Open Access This article is licensed under a Creative Commons Attribution 4.0 International License, which permits use, sharing, adaptation, distribution and reproduction in any medium or format, as long as you give appropriate credit to the original author(s) and the source, provide a link to the Creative Commons licence, and indicate if changes were made. The images or other third party material in this article are included in the article's Creative Commons licence, unless indicated otherwise in a credit line to the material. If material is not included in the article's Creative Commons licence and your intended use is not permitted by statutory regulation or exceeds the permitted use, you will need to obtain permission directly from the copyright holder. To view a copy of this licence, visit http://creativecommons.org/licenses/by/4.0/.

\section{References}

1. Spencer M (1986) Stable and metastable metal-surfaces in heterogeneous catalysis. Nature 323(6090):685-687. https://doi.org/10. 1038/323685a0

2. Brune H, Roder H, Boragno C, Kern K (1994) Microscopic view of nucleation on surfaces. Phys Rev Lett 73(14):1955-1958. https://doi.org/10.1103/PhysRevLett.73.1955

3. Brune H, Bales GS, Jacobsen J, Boragno C, Kern K (1999) Measuring surface diffusion from nucleation island densities. Phys Rev B 60(8):5991-6006. https://doi.org/10.1103/PhysRevB.60.5991 
4. Spencer M (1985) Models of strong metal support interaction (SMSI) in Pt on $\mathrm{TiO}_{2}$ catalysts. J Catal 93(2):216-223. https:// doi.org/10.1016/0021-9517(85)90169-1

5. Burgess R, Buono C, Davies PR, Davies RJ, Legge T, Lai A, Lewis R, Morgan DJ, Robinson N, Willock DJ (2015) The functionalisation of graphite surfaces with nitric acid: identification of functional groups and their effects on gold deposition. J Catal 323:10-18. https://doi.org/10.1016/j.jcat.2014.12.021

6. Buono C, Davies PR, Davies RJ, Jones T, Kulhavý J, Lewis R, Morgan DJ, Robinson N, Willock DJ (2014) Spectroscopic and atomic force studies of the functionalisation of carbon surfaces: new insights into the role of the surface topography and specific chemical states. Faraday Discuss 173:257-272. https://doi.org/10. 1039/C4FD00061G

7. Bowden B, Davies M, Davies PR, Guan S, Morgan DJ, Roberts V, Wotton D (2018) The deposition of metal nanoparticles on carbon surfaces: the role of specific functional groups. Faraday Discuss 208:455-470. https://doi.org/10.1039/C7FD00210F

8. Derbyshire FJ, de Beer VHJ, Abotsi GMK, Scaroni AW, Solar JM, Skrovanek DJ (1986) The influence of surface functionality on the activity of carbon-supported catalysts. Appl Catal 27(1):117-131. https://doi.org/10.1016/S0166-9834(00)81051-9

9. Radovic LR, Rodriguez-Reinoso F (1997) Carbon materials in catalysis. In: Thrower PA (ed) Chemistry and physics of carbon, vol 25. Marcel Dekker, New York, pp 243-358

10. García-García FR, Gallegos-Suarez E, Fernández-García M, Guerrero-Ruiz A, Rodríguez-Ramos I (2017) Understanding the role of oxygen surface groups: the key for a smart rutheniumbased carbon-supported heterogeneous catalyst design and synthesis. Appl Catal Gen 544:66-76. https://doi.org/10.1016/j.apcata. 2017.06.030

11. Xu J, Zhao J, Xu J, Zhang T, Li X, Di X, Ni J, Wang J, Cen J (2014) Influence of surface chemistry of activated carbon on the activity of gold/activated carbon catalyst in acetylene hydrochlorination. Ind Eng Chem Res 53(37):14272-14281. https://doi.org/ 10.1021/ie502683r

12. Goncalves G, Marques PAAP, Granadeiro CM, Nogueira HIS, Singh MK, Grácio J (2009) Surface modification of graphene nanosheets with gold nanoparticles: the role of oxygen moieties at graphene surface on gold nucleation and growth. Chem Mater 21(20):4796-4802. https://doi.org/10.1021/cm901052s

13. Bouleghlimat E, Davies PR, Davies RJ, Howarth R, Kulhavy J, Morgan DJ (2013) The effect of acid treatment on the surface chemistry and topography of graphite. Carbon 61:124-133. https://doi.org/10.1016/j.carbon.2013.04.076

14. Johnston P, Carthey N, Hutchings GJ (2015) Discovery, development, and commercialization of gold catalysts for acetylene hydrochlorination. J Am Chem Soc 137(46):14548-14557. https:// doi.org/10.1021/jacs.5b07752

15. Horcas I, Fernandez R, Gomez-Rodriguez J, Colchero J, GomezHerrero J, Baro A (2007) WSXM: a software for scanning probe microscopy and a tool for nanotechnology. Rev Sci Instrum 78(1):013705

16. Militello MC, Simko SJ (1994) Palladium chloride (PdCl2) by XPS. Surf Sci Spectra 3(4):402-409. https://doi.org/10.1116/1. 1247785

17. Choudary BM, Kumar KR, Jamil Z, Thyagarajan G (1985) A novel 'anchored' palladium(ii) phosphinated montmorillonite: the first example in the interlamellars of smectite clay. J Chem Soc Chem Commun 13:931-932. https://doi.org/10.1039/C398500009 31

18. Zhang Z, Xu M, Ho W, Zhang X, Yang Z, Wang X (2016) Simultaneous excitation of $\mathrm{PdCl} 2$ hybrid mesoporous G-C3N4 molecular/solid-state photocatalysts for enhancing the visiblelight-induced oxidative removal of nitrogen oxides. Appl Catal B 184:174-181. https://doi.org/10.1016/j.apcatb.2015.11.034

19. Bowden B, Davies M, Davies PR, Guan S, Morgan D, Roberts V, Wotton DJ (2018) The deposition of metal nanoparticles on carbon surfaces: the role of specific functional groups. Faraday Discuss. https://doi.org/10.1039/C7FD00210F

20. Drew Tait C, Janecky DR, Rogers PSZ (1991) Speciation of aqueous palladium(II) chloride solutions using optical spectroscopies. Geochim Cosmochim Acta 55(5):1253-1264. https://doi.org/10. 1016/0016-7037(91)90304-N

21. Cruywagen JJ, Kriek RJ (2007) Complexation of palladium(II) with chloride and hydroxide. J Coord Chem 60(4):439-447. https://doi.org/10.1080/00958970600873588

22. Zuccaro L, Krieg J, Desideri A, Kern K, Balasubramanian K (2015) Tuning the isoelectric point of graphene by electrochemical functionalization. Sci Rep 5:11794. https://doi.org/10.1038/ srep11794

23. Malta G, Kondrat SA, Freakley SJ, Davies CJ, Lu L, Dawson S, Thetford A, Gibson EK, Morgan DJ, Jones W, Wells PP, Johnston P, Catlow CRA, Kiely CJ, Hutchings GJ (2017) Identification of single-site gold catalysis in acetylene hydrochlorination. Science 355(6332):1399-1403. https://doi.org/10.1126/science.aal3439

24. NIST (2012) X-ray photoelectron spectroscopy database. National Institute of Standards and Technology, Gaithersburg

25. Abraham KM, Chaudhri SM (1986) The lithium surface film in the Li/SO 2 cell. J Electrochem Soc 133(7):1307. https://doi.org/ $10.1149 / 1.2108858$

26. Hohlneicher G, Pulm H, Freund HJ (1985) On the separation of initial and final state effects in photoelectron spectroscopy using an extension of the auger-parameter concept. J Electron Spectrosc Relat Phenom 37(2):209-224. https://doi.org/10.1016/03682048(85)80069-4

27. Kaden WE, Büchner C, Lichtenstein L, Stuckenholz S, Ringleb F, Heyde M, Sterrer M, Freund HJ, Giordano L, Pacchioni G, Nelin CJ, Bagus PS (2014) Understanding surface core-level shifts using the auger parameter: a study of pd atoms adsorbed on ultrathin $\mathrm{SiO}_{2}$ films. Phys Rev B 89(11):115436. https://doi.org/10.1103/ PhysRevB.89.115436

28. Ringleb F, Sterrer M, Freund HJ (2014) Preparation of Pd-MgO model catalysts by deposition of $\mathrm{Pd}$ from aqueous precursor solutions onto $\mathrm{Ag}(001)$-supported $\mathrm{MgO}(001)$ thin films. Appl Catal Gen 474:186-193. https://doi.org/10.1016/j.apcata.2013.05.031

29. Moreau F, Bond GC, Taylor AO (2005) Gold on titania catalysts for the oxidation of carbon monoxide: control of $\mathrm{PH}$ during preparation with various gold contents. J Catal 231(1):105-114. https:// doi.org/10.1016/j.jcat.2005.01.030

Publisher's Note Springer Nature remains neutral with regard to jurisdictional claims in published maps and institutional affiliations. 


\section{Authors and Affiliations}

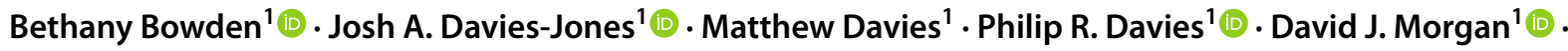
Mala A. Sainna ${ }^{1}$ (1) - David J. Willock ${ }^{1}$

$\triangle$ Philip R. Davies

daviespr@cardiff.ac.uk
Cardiff Catalysis Institute, School of Chemistry, Cardiff University, Cardiff CF10 3AT, UK 